\title{
Differential effects of intra-amygdala lidocaine infusion on memory consolidation and expression of a food conditioned place preference
}

\author{
JASON P. SCHROEDER and MARK G. PACKARD \\ Yale University, New Haven, Connecticut
}

\begin{abstract}
In the present experiments, we examined the effects of posttraining and preretention intra-amygdala infusion of the anesthetic lidocaine on memory consolidation and expression in a food conditioned place preference (CPP) task. In two separate experiments, for 4 alternating days, food deprived adult male Long-Evans rats were given access to food or no access to food during confinement for $30 \mathrm{~min}$ to one of two compartments in a place preference apparatus. On Day 9, the rats were given a 20 -min test session and allowed access to all compartments of the apparatus. No food was present on the test day, and the amount of time spent in each compartment of the apparatus was recorded. On the test day, rats receiving saline immediately after previous training, or immediately prior to testing, spent more time in the compartment that was previously paired with food, demonstrating a food conditioned place preference (CPP). Posttraining infusion of lidocaine ( $2 \%$ solution, $0.5 \mu \mathrm{V}$ side) into the basolateral amygdala blocked acquisition, indicating that this structure is necessary for memory consolidation processes that mediate a food CPP. In contrast, immediate pretest infusion of lidocaine into the basolateral amygdala had no effect on expression of a food CPP. Taken together, the findings suggest a modulatory role for the basolateral amygdala in memory consolidation processes that underlie reward-related learning in a food CPP task.
\end{abstract}

The conditioned place preference (CPP) paradigm is commonly used to infer the rewarding properties of various substances by assessing the extent to which stimuli that have been paired with treatment administration elicit approach responses in the absence of the treatment on the test day (for reviews, see Carr, Fibiger, \& Phillips, 1989; Schechter \& Calcagnetti, 1993). Drugs of abuse including amphetamine, cocaine, diazepam, nicotine, and morphine, as well as naturally occurring stimuli such as food, water, or exposure of male rats to a receptive female, produce CPPs (Carr et al., 1989; Schechter \& Calcagnetti, 1993).

One overlooked aspect of the CPP paradigm is that it offers an opportunity to assess not only the development of primary reward, but also memory for the rewarding consequences of various treatments (White \& Carr, 1985). Specifically, because subjects are in a treatment-free state on the test day, expression of a CPP requires memory for the association between environmental cues and the affective state produced by the treatment. An important role of the memory enhancing properties of treatments in the CPP paradigm was demonstrated in a study examining the rewarding effects of glucose and saccharin. Both of these substances are orally consumed in preference tests, suggesting that on the basis of their gustatory

This research was supported by NIH Grant R29MH056973 to M.G.P. We thank Daniel Sanchez and Shibani Mukerii for surgical and histological assistance. Correspondence should be addressed to M. G. Packard, Yale University, Department of Psychology, New Haven, CT 06520 (e-mail: mark.packard@yale.edu). input, they both possess rewarding affective properties (White \& Carr, 1985). However, glucose, but not saccharin, has the additional properties of producing a CPP following systemic injection and enhancing memory in several tasks when administered posttraining (e.g., Gold, 1986; Messier \& White, 1984; Packard \& White, 1990; White \& Carr, 1985). Importantly, although systemic injections of saccharin are not capable of producing a CPP, additional posttraining administration of glucose has been shown to induce a saccharin CPP (White \& Carr, 1985). Taken together, these findings suggest that acquisition of a CPP is dependent on both a treatment's ability to produce a rewarding affective state and its memory enhancing effect. Consistent with this hypothesis, other substances that produce a CPP (e.g., amphetamine and cocaine), also enhance memory when injected posttraining (e.g., Cestari, Mele, Oliverio, \& Castellano, 1996; Doty \& Doty, 1966; Packard \& White, 1989). In addition to memory enhancement, posttraining treatments can be used to block or attenuate memory in the CPP paradigm. For example, intracerebroventricular infusion of protein kinase inhibitors block a cocaine CPP (Cervo, Mukherjee, Bertaglia, \& Samanin, 1997).

Recent studies examining the neuroanatomical bases of reward-related learning and memory as measured in the CPP task have implicated the basolateral/lateral amygdala. For example, pretraining quinolinic acid lesions of the amygdala block acquisition of a cocaine CPP (Brown \& Fibiger, 1993), and electrolytic and excitotoxic lesions of the lateral amygdaloid nucleus prevent the acquisition and expression of an amphetamine CPP (Hiroi \& White, 
1991). In addition to psychostimulant drug treatments, the use of naturally occurring stimuli in the CPP task has also implicated amygdala function in CPP behavior. Thus, pretraining electrolytic lesions of the lateral nucleus of the amygdala block acquisition of a food CPP in the eight-arm radial maze (McDonald \& White, 1993), and acquisition/expression of a CPP for sucrose is abolished by excitotoxic lesions of the basolateral amygdala (Everitt, Morris, O’Brien, \& Robbins, 1991). Finally, pretraining infusion of the acetylcholine antagonist scopolamine into the amygdala prevents acquisition of a food CPP (McIntyre, Ragozzino, \& Gold, 1998).

Although previous findings clearly implicate the amygdala in CPP behavior, the extent to which these manipulations influence memory processes in the CPP task can be difficult to assess in studies that employ pretraining or pretest lesion techniques. Such treatments may influence CPP acquisition and/or expression by impairing memory, primary reward, or nonmnemonic sensory, motivational, or motoric processes. Although the contribution of nonmnemonic factors in amygdala mediation of rewardrelated learning have been indirectly addressed in studies that have revealed dissociations following amygdala lesions in different types of learning tasks (e.g., Burns, Everitt, \& Robbins, 1993; Everitt et al., 1991; McDonald \& White, 1993), the present experiments were designed to directly examine the role of this structure in memory processes underlying a food CPP. Specifically, saline or the local anesthetic lidocaine were infused immediately posttraining into the basolateral amygdala to examine the role of this structure in memory consolidation processes (McGaugh, 1966, 1973, 1989) mediating a food CPP.

In addition to examining the effects of posttraining intrabasolateral amygdala infusion of lidocaine, the question of whether the amygdala plays a differential role in memory consolidation and expression of a food CPP was assessed. This question is of interest in view of evidence that, for at least some learning tasks, posttraining amygdala activation modulates memory storage processes that occur in other brain sites (e.g., hippocampus and caudate-putamen), rather than its serving as a site of permanent memory storage (Packard, Cahill, \& McGaugh, 1994; Packard, Cahill, Williams, \& McGaugh, 1995; Packard \& Teather, 1998). Evidence from studies employing permanent lesion techniques indicates a role for the amygdala in CPP expression for both amphetamine (lateral amygdala; Hiroi \& White, 1991) and sucrose (basolateral/lateral amygdala; Everitt et al., 1991). In an additional experiment, saline or lidocaine was infused into the basolateral amygdala prior to the test session to determine whether this structure also mediates expression of a food CPP.

\section{METHOD}

\section{Subjects}

The subjects were 30 adult male Long-Evans rats $(300-375 \mathrm{~g})$. The rats were individually housed in a temperature-controlled en- vironment on a 12:12-h light:dark cycle with the lights on from 7 am to $7 \mathrm{pm}$ and were given ad-lib access to food and water prior to surgery.

\section{Apparatus}

The apparatus was constructed of wood and had a Plexiglas front wall. It consisted of three compartments, two of which were identical in size $(45 \times 45 \times 30 \mathrm{~cm}$ high). One compartment was painted black and had a black Plexiglas floor and $1 \mathrm{ml}$ of a $1 \%$ acetic acid solution sprayed on the walls prior to training and testing. The other compartment was painted white and had a white Plexiglas floor. These two compartments were separated from each other by a wooden partition and were connected by the thitd compartment. The gray roofed tunnel $(36 \times 18 \times 20 \mathrm{~cm}$ high) had a metal floor and could be opened to allow entrance into each of the two larger compartments.

\section{Surgery}

Prior to surgery, the subjects were anesthetized with a cocktail of $30-\mathrm{mg} / \mathrm{kg}$ ketamine $\mathrm{HCl}$ and $2.5-\mathrm{mg} / \mathrm{kg}$ xylazine. Bilateral guide cannulae $(15 \mathrm{~mm}$ in length) were implanted overlying the basolateral amygdala by $1 \mathrm{~mm}$, using standard stereotaxic techniques. Jeweler's screws were anchored to the skull and attached to the cannulae with dental acrylic. Stereotaxic coordinates for the basolateral amygdala placements were $\mathrm{AP}=-2.2 \mathrm{~mm}, \mathrm{ML}=4.7$ from bregma, and DV $=-7.0 \mathrm{~mm}$ from the skull surface. After surgery, stylets were inserted and left in the cannulae until the time of injection. The subjects were allowed 1 week of recovery before food deprivation was initiated.

\section{Injection Procedures}

The intra-amygdala infusions were administered via a microsyringe pump using a $10-\mu$ l Hamilton syringe connected to polyethylene tubing. The infusions were administered over a $53-\mathrm{sec}$ period, and the injection needles were left in place an additional $60 \mathrm{sec}$ to allow for diffusion. Injection volume was $0.5 \mu \mathrm{l}$ for both saline and lidocaine ( $2 \%$ solution, $10 \mu \mathrm{g} /$ side) injections. This dose and volume of lidocaine was chosen on the basis of our previous findings, which indicated that it is behaviorally effective when administered into the amygdala (Packard \& Chen, 1999; Packard \& Teather, 1998). Electrophysiological evidence indicates that intracerbral injection of this concentration of lidocaine solution depresses neural function within 2 min of infusion, with a duration of approximately $30 \mathrm{~min}$ (Tehovnik \& Sommer, 1997). This consideration is important in view of our use of a 20 -min session on the test day in the CPP task.

\section{Histology}

Following behavioral testing, the animals were deeply anesthetized with a $1-\mathrm{ml}$ injection of sodium pentobarbital $(50 \mathrm{mg} / \mathrm{kg})$ and perfused with saline followed by $10 \%$ formol-saline. The brains were removed and sectioned at $20 \mu \mathrm{m}$. They were then stained with cresyl violet, and cannula placements were verified using the atlas of Paxinos and Watson (1986). As illustrated in Figure 1, injection needle tips were located in the basolateral nucleus of the amygdala, ranging from -2.12 to $-2.8 \mathrm{~mm} \mathrm{AP}$ from bregma.

\section{Behavioral Procedures}

One week following surgery, the rats were reduced to $85 \%$ of their ad-lib feeding weight over an additional 7-day period. CPP training took place over 6 days, and the parameters were chosen on the basis of pilot data indicating that they produced a significant food CPP. The 1 st day consisted of habituation, during which the subjects were allowed access to all three compartments of the CPP apparatus for $10 \mathrm{~min}$. The next 4 days consisted of two food and two nonfood pairings, during which the subjects were confined to a compartment containing $7 \mathrm{~g}$ of Noyes food pellets scattered on the floor, or no food. Half of the subjects had access to food during exposure 

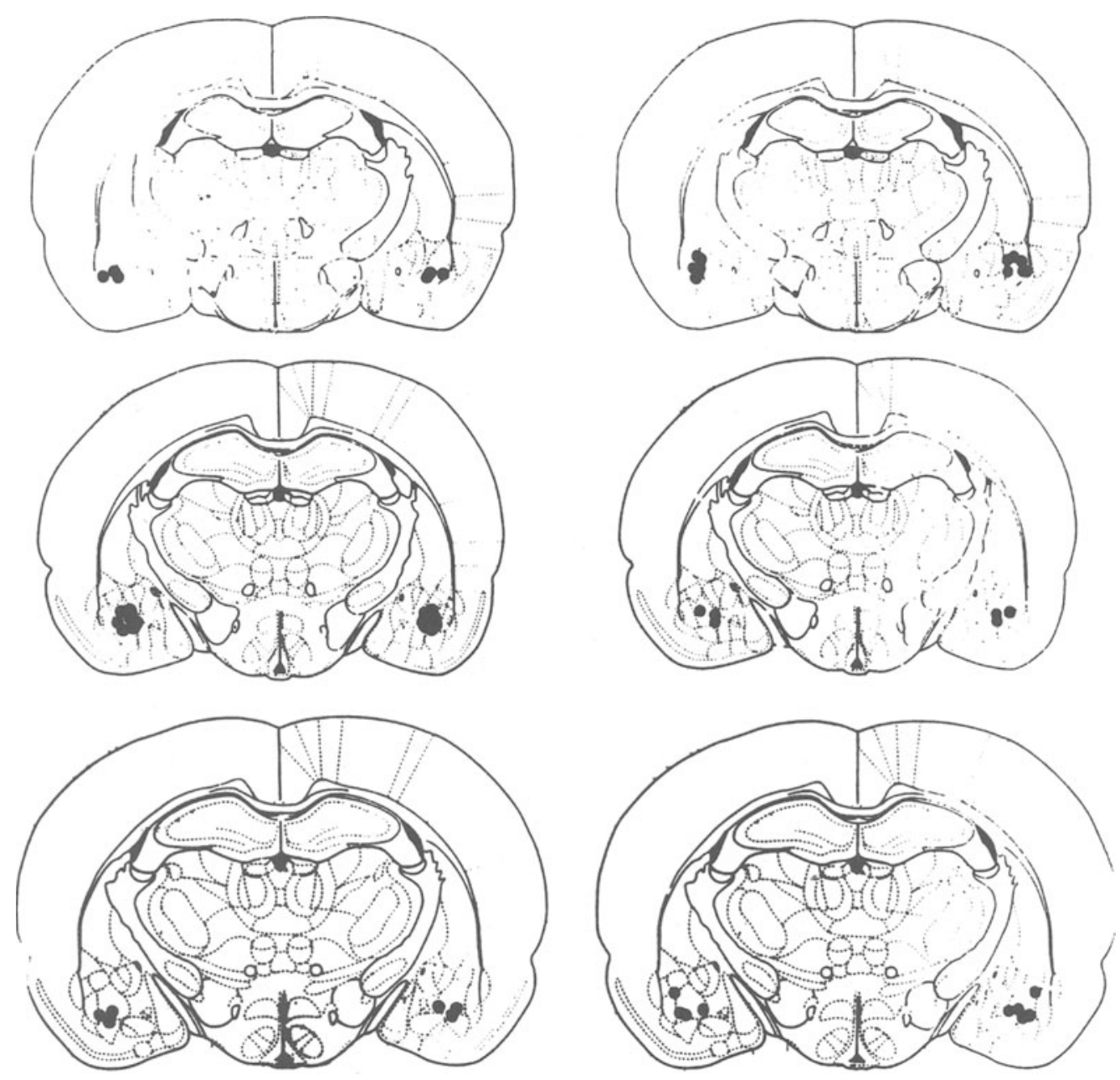

Figure 1. Location of cannula placements in the basolateral amygdala. The placements ranged from -2.12 to $-\mathbf{2 . 8} \mathbf{~ m m}$ anterior-posterior to bregma (Paxinos \& Watson, 1986) for both infusions made posttraining (left column) and pretesting (right column).

to the black compartment and no access to food during exposure to the white compartment. The remaining subjects had access to food during exposure to the white compartment and no access to food during exposure to the black compartment. Half of the subjects had access to food on odd numbered days, and half had access to food on even numbered days. Following the 4 training days, the subjects were given a 20 -min test session during which they were allowed access to all three compartments of the CPP apparatus with no food present. Time spent in each of the compartments was recorded.

To examine the effects of posttraining intrabasolateral amygdala infusion of lidocaine, the subjects received bilateral infusions of lidocaine $(n=6)$ or saline $(n=8)$ immediately following removal from their paired (i.e., food) and unpaired compartments on each of the training days, and on the test day, the subjects were allowed access to all three compartments of the apparatus with no food present. To examine the effects of pretesting infusions of lidocaine, the subjects received bilateral infusions of lidocaine $(n=8)$ or saline $(n=8)$ immediately prior to the 20 -min test session in the food CPP paradigm.

\section{Results}

Posttraining intra-amygdala lidocaine infusions. Figure 2 shows the amount of time spent in the paired and unpaired compartments on the test day. A two-way one repeated measure analysis of variance (ANOVA) with posttraining infusion as an independent variable and paired versus unpaired side as a repeated measure revealed a significant interaction $[F(1,12)=26.48, p<.01]$. Post hoc two-tailed paired $t$ tests revealed that the subjects receiving posttraining intrabasolateral amygdala saline infusions spent significantly more time in the food paired compartment than in the nonfood paired compartment $[t(7)=6.30, p<.05]$, indicating a food CPP. In contrast, the rats receiving posttraining intrabasolateral amygdala lidocaine infusions did not spend different amounts of time in the food and nonfood paired compartments $[t(5)=$ $1.27, \mathrm{n.s}$.$] . These findings indicate a blockade of a food-$ CPP by posttraining infusions of lidocaine into the basolateral amygdala.

Pre-test intra-amygdala lidocaine infusions. Figure 3 shows the amount of time spent in the paired and unpaired compartments on the test day. A two-way one repeated measure ANOVA with posttraining infusion as 


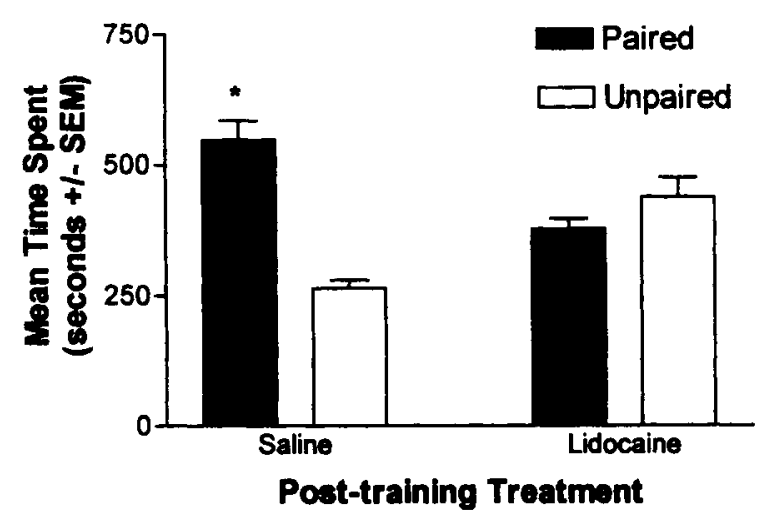

Figure 2. Effect of posttraining intrabasolateral amygdala infusion of lidocaine on place-memory consolidation of a food conditioned place preference. Mean time spent (second $\pm S E M$ ) during a 20-min test session in the previously paired (food) and unpaired (no food) compartments of the place preference apparatus. *Significant place preference.

an independent variable and paired versus unpaired side as a repeated measure revealed no significant interaction $[F(1,14)=0.45$, n.s. $]$. A significant effect of side $[F(1,14)=21.1, p<.01]$ indicated a significant food $\mathrm{CPP}$ in rats infused with either saline or lidocaine immediately prior to testing.

\section{DISCUSSION}

The findings indicate that posttraining infusions of lidocaine into the basolateral amygdala block memory consolidation processes mediating a food CPP. This finding is consistent with the impairing effects of pretraining basolateral/lateral amygdala lesions on acquisition of drug (Brown \& Fibiger, 1993; Hiroi \& White, 1991), sucrose (Everitt et al., 1991), and food-induced (McDonald \& White, 1993) CPPs. However, in previous studies using pretraining amygdala lesions, the impairing effects observed in CPP behavior may have been due to an influence on learning and/or memory per se, or on nonmnemonic factors such as primary reward, sensory processes, or motivation. The contribution of such factors to amygdala lesion-induced impairments in CPP behavior appear unlikely in view of evidence that similar lesions do not effect acquisition of other types of learning tasks with similar nonmnemonic characteristics (e.g., Cador, Robbins, \& Everitt, 1989; Everitt et al., 1991; McDonald \& White, 1993). Nonetheless, our findings using a reversible posttraining lesion technique clearly suggest a role for the basolateral amygdala in memory processes underlying a food CPP (i.e., consolidation; McGaugh, 1966, 1973, 1989). Moreover, they raise the possibility that the impairment produced by pretraining lesions are due, at least in part, to the absence of a functional amygdala during the posttraining period.

Pretest infusion of lidocaine into the basolateral amygdala did not block expression of a food CPP, suggesting that in this task, expression of approach responses to conditioned stimuli associated with the rewarding affective properties of food does not require basolateral amygdala function. Electrophysiological evidence indicates that intracerebral injection of a $2 \%$ lidocaine solution depresses neural function within 2 min of infusion and has a duration of approximately $30 \mathrm{~min}$ (Tehovnik \& Sommer, 1997), suggesting that neural inactivation was present during the 20-min test session in our CPP task. However, our findings stand in contrast to those of previous studies examining the effects of excitotoxic or electrolytic lesions of the basolateral/lateral amygdala on expression of various CPPs. For example, pretest quinolinic acid lesions of the basolateral amygdala prevented expression of a sucrose CPP (Everitt et al., 1991), and electrolytic or NMDA-induced lesions of the lateral amygdala prior to the test day blocked expression of an amphetamine CPP (Hiroi \& White, 1991). Although the use of excitotoxic lesions have the important advantage of sparing neuronal fibers of passage, the amygdaloid complex is highly susceptible to seizure activity, and excitotoxic lesions of the amygdala have been found to cause damage to associated limbic and cortical structures (e.g., Berger, Charton, \& Ben-Ari, 1986). This raises the possibility that extra-amygdala damage (e.g., perirhinal cortex, as described in the study of Everitt et al., 1991) may have contributed to the behavioral impairments observed during CPP expression. In the latter study (Hiroi \& White, 1991), blockade of expression of an amphetamine CPP was observed with lesions primarily restricted to the lateral amygdala. It is possible that expression of an amphetamine, but not a food CPP requires amygdala function. Alternatively, lidocaine infusion into the basolateral site targeted in the present study may not have adequately inactivated more lateral regions of the amygdala that could conceivably be involved in the expression of a

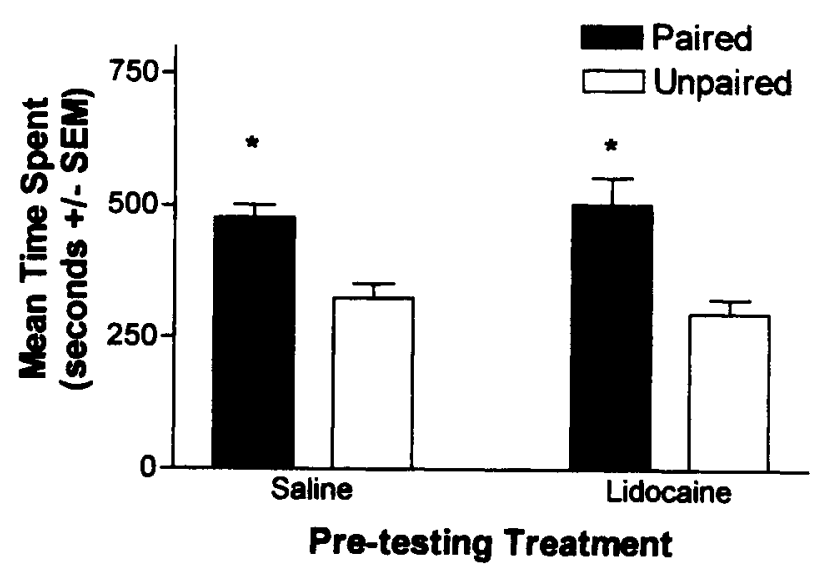

Figure 3. Effect of pretesting intrabasolateral amygdala infusion of lidocaine on expression of place memory of a food conditioned place preference. Mean time spent (second $\pm S E M$ ) during a 20-min test session in the previously paired (food) and unpaired (no food) compartments of the place preference apparatus. *Significant place preference. 
food CPP. According to this view, given that our basolateral injection site was effective when lidocaine was infused posttraining, it is possible that the basolateral amygdala modulates the lateral amygdala during CPP consolidation, and that the lateral amygdala is therefore necessary for CPP expression. However, although our injection sites were within the basolateral nucleus, in view of the injection volume used $(0.5 \mu \mathrm{l})$, it is unlikely that lidocaine selectively affected this amygdaloid nucleus. Further studies targeting different amygdala nuclei and employing smaller injection volumes are clearly necessary to examine the possibility of a differential role of amygdaloid nuclei in mediating memory consolidation and expression of CPP behavior.

Taken together, the present patterns of results, in which intrabasolateral infusions of lidocaine block memory consolidation processes but not behavioral expression of a food CPP, suggest either multiple storage sites (i.e., amygdala and other brain sites) for stimulus reward associations, or a temporary nonstorage "modulatory" role for the amygdala in memory for conditioned reward. These findings are similar to those of studies demonstrating a time-dependent role of the amygdala in memory in other types of learning tasks (e.g., McGaugh, Cahill, \& Roozendaal, 1996; Packard et al., 1995; Parent, West, \& McGaugh, 1994; Poremba \& Gabriel, 1999). For example, posttraining intra-amygdala injections of amphetamine enhance memory in hippocampaldependent and caudate nucleus-dependent hidden and visible platform water maze tasks (Packard et al., 1994; Packard \& Teather, 1998), respectively. Importantly, the memory enhancement produced by intra-amygdala amphetamine in these tasks is not due to storage of memory within this structure, since preretention intra-amygdala injections of lidocaine do not prevent expression of amphetamine's memory enhancing effects (Packard et al., 1994; Packard \& Teather, 1998). In contrast, concurrent posttraining infusion of lidocaine into the hippocampus selectively blocks the memory enhancing effects of intraamygdala injection of amphetamine in a hidden platform task, whereas similar infusion of lidocaine into the caudate-putamen selectively blocks the memory enhancing effects of intra-amygdala injection of amphetamine in a visible platform task (Packard \& Teather, 1998). Thus, independent hippocampal and caudate-putamen memory systems, which both receive efferent basolateral amygdala projections (Finch et al., 1986; Kita \& Kitai, 1990; Krettek \& Price, 1977, 1978; McDonald, 1991; Russchen \& Price, 1984), appear to be two targets of the memory modulatory influence of the amygdala.

An important question concerns identification of the brain region(s) that may receive a memory modulatory influence from the basolateral amygdala in the CPP task. Previous evidence suggests that hippocampal and caudateputamen memory systems are unlikely candidates for amygdala modulation in this particular task, since lesions of these structures do not affect CPP acquisition for either amphetamine (e.g., Hiroi \& White, 1991), or food (Mc-
Donald \& White, 1993). However, the nucleus accumbens receives prominent projections from the basolateral amygdala (Kita \& Kitai, 1990; Krettek \& Price, 1978; McDonald, 1991; Russchen \& Price, 1984), and evidence from pharmacological and lesion studies implicate the nucleus accumbens in the acquisition and expression of CPPs for various drug treatments and naturally occurring stimuli (for reviews, see Carr et al., 1989; Schechter \& Calcagnetti, 1993). Moreover, the nucleus accumbens appears to interact with basolateral amygdala function in stimulus-reward learning (for reviews see Cador et al., 1989; Everitt \& Robbins, 1992). Amygdalo-striatal projections are unidirectional in nature (Kita \& Kitai, 1990), and this pathway has been suggested to provide the basolateral amygdala access to motor output involved in behavioral expression of stimulus-reward learning (e.g., Everitt et al., 1991). Alternatively, this pathway could conceivably allow the basolateral amygdala to exert a modulatory influence on long-term synaptic plasticity in the nucleus accumbens, a time-limited process in which behavioral expression would ultimately be independent of amygdala function. The latter suggestion is consistent with the present observation of lidocaine-induced blockade of memory consolidation, but not the expression of a food CPP, and with recent findings indicating that lesions of the basolateral amygdala block the ability of drug-associated stimuli to reinstate responding for cocaine after 21 days, but not after 43 days of drug withdrawal (Meil $\&$ See, 1997). Thus, further studies examining basolateral amygdala-nucleus accumbens interactions may aid our understanding of the modulatory role of the amygdala on consolidation of stimulus-reward memory.

\section{REFERENCES}

Berger, M. L., Charton, G., \& Ben-Arı, Y. ( 1986). Effect of seizures induced by intra-amygdala kainic acid on kainic acid binding sites in rat hippocampus and amygdala. Journal of Neurochemistry, 47, 720-727.

Brown, E., \& Fibiger, H. (1993). Differential effects of excitotoxic lesions of the amygdala on cocaine-induced conditioned locomotion and conditioned place preference. Psycholopharmacologv, 113, 123-130.

Burns, L. H., EveritT, B. J., \& RobBins, T. W. (1993). Differential effects of excitotoxic lesions of the basolateral amygdala, ventral subiculum and medial prefrontal cortex on responding with conditioned reinforcement and locomotor activity potentiated by intra-accumbens infusions of $d$-amphetamine. Behavioural Brain Research, 55, 167-183.

Cador, M., Robbins, T. W., \& EveritT, B. J. (1989). Involvement of the amygdala in stimulus-reward associations: Interaction with the ventral striatum. Neuroscience, 30, 77-86

Carr, G. D., Fibiger, H. C., \& Phillips, A. G. (1989). Conditioned place preference as a measure of drug reward. In J. M. Leibman \& S. J. Cooper (Eds.), Oxford reviews in psychopharmacology: Vol. 1. Neuropharmacological basis of reward (pp. 265-319). New York: Oxford University Press.

Cervo, L., Mukherjee, S.. Bertaglia, A., \& Samanin. R. (1997). Protein kinases $A$ and $C$ are involved in the mechanisms underlying consolidation of cocaine place conditioning. Brain Research, 775, 30-36.

Cestari, V., Mele, A., Oliverio, A., \& Castellano, C. (1996). Amygdala lesions block the effect of cocaine on memory in mice. Brain Research, 713, 286-289. 
Doty, B., \& Doty, L. A. (1966). Facilitative effects of amphetamine on avoidance conditioning in relation to age and problem difficulty. Psychopharmacologia, 9, 234-241.

Everitt, B. J., Morris, K. A., O'Brien, A.. \& Robbins, T. W. (1991) The basolateral amygdala-ventral striatal system and conditioned place preference: Further evidence of limbic-striatal interactions underlying reward-related processes. Neuroscience, 42, 1324-1334.

Everitt, B. J., \& RobBins, T. W. (1992). Amygdala-ventral striatal interactions and reward related processes. In J. P. Aggleton (Ed.), The amygdala: Neurobiological aspects of emotion, memory, and mental dysfunction (pp. 401-429). New York: Wiley-Liss.

Finch, D. M., Wong, E. E., Derian, E. L., Chen, X. H., NowlinFinCH, N. L.. \& Brothers, L. E. (1986). Neurophysiology of limbic system pathways in the rat: Projections from the amygdala to the entorhinal cortex. Brain Research, 370, 273-284.

GolD, P. E. (1986). Glucose modulation of memory storage processing. Behavioral \& Neural Biology, 45, 342-349.

HiRoI, N., \& WHITE, N. M. (1991). The lateral nucleus of the amygdala mediates expression of amphetamine-produced place preference. Journal of Neuroscience, 11, 2107-2116.

KiTA, H., \& KITAl, S. T. (1990). Amygdaloid projections to the frontal cortex and the striatum in the rat. Journal of Comparative Neurology, 298. $40-49$.

Krettek, J. E., \& Price, J. L. (1977). Projections from the amygdaloid complex and adjacent olfactory structures to the entorhinal cortex and subiculum in the rat and cat. Journal of Comparative Neurology, 178, 723-752.

Krettek, J. E., \& Price, J. L. (1978). Amygdaloid projections to subcortical structures within the basal forebrain and brainstem in the rat and cat. Journal of Comparative Neurology, 178, 225-254.

MCDONALD, A. J. (1991). Topographical organization of amygdaloid projections to the caudatoputamen, nucleus accumbens, and related striatal-like areas of the rat brain. Neuroscience, 44, 15-33.

MCDONALD, R. J.. \& White. N. M. (1993). A triple dissociation of memory systems: Hippocampus, amygdala, and dorsal striatum. Behavioral Neuroscience, 107, 3-22.

McGaugh, J. L. (1966). Time-dependent processes in memory storage. Science, 153. 1351-1358.

MCGAUGH. J. L. (1973). Drug facilitation of learning and memory. Annual Review of Pharmacologv, 13, 229-240.

MCGaugh, J. L. (1989). Dissociating learning and performance: Drug and hormone enhancement of memory storage. Brain Research Bulletin, 23, 339-345.

McGaugh, J. L.. Cahil... L., \& Roozendal, B. (1996). Involvement of the amygdala in memory storage: Interaction with other brain systems. Proceedings of the National Academy of Sciences, 93. 13508-13514.

MCINTYRe, C., Ragozzino, M.. \& Gold), P. (1998), Intra-amygdala infusions of scopolamine impair performance on a conditioned place preference task but not a spatial radial maze task. Behavioural Brain Research. 95, 219-226.

MEIL. W. M.. \& SEE, R. F. (1997). Lesions of the basolateral amygdala abolish the ability of drug associated cues to reinstate responding during withdrawal from self-administered cocaine. Behavioural Brain Research, 87, 139-148.

Messier, D., \& White, N. M. (1984). Contingent and non-contingent actions of sucrose and saccharin reinforcers: Effects on taste preference and memory. Physiology \& Behavior, 32, 195-203.

Packard, M. G., Cahill, L., \& McGaugh, J. L. (1994). Amygdala modulation of hippocampal-dependent and caudate nucleus-dependent memory processes. Proceedings of the National Academy of Sciences, 91, 8477-8481.

Packard, M. G., Cahill, L., Williams, C. L., \& McGaugh, J. L. (1995). The anatomy of a memory modulatory system: From periphery to brain. In N. E. Spear, L. P. Spear, \& M. L. Woodruff (Eds.), Neurobehavioral plasticity: Learning, development, and response to brain insults (pp. 149-183). Hillsdale, NJ: Erlbaum.

Packard, M. G., \& Chen, S. A. (1999). The basolateral amygdala is a cofactor in memory enhancement produced by intrahippocampal glutamate injections. Psychobiology, 27, 377-385.

Packard, M. G., \& Teather, L. A. (1998). Amygdala modulation of multiple memory systems: Hippocampus and caudate-putamen. Neurobiology of Learning \& Memory, 69, 163-203.

Packard. M. G., \& White, N. M. (1989). Memory facilitation produced by dopamine agonists: Role of receptor subtype and mnemonic requirements. Pharmacology, Biochemistry, \& Behavior, 33, 511-518.

Packard, M. G., \& White, N. M. (1990). Effect of posttraining injections of glucose on acquisition of two appetitive learning tasks. $P s y$ chobiology, 18, 282-286.

Parent, M. B., West, M., \& MCGaugh, J. L. (1994). Memory of rats with amygdala lesions induced 30 days after footshock-motivated escape training reflects degree of original training. Behavioral Neuroscience, 108, 1080-1087.

Paxinos, G., \& Watson, C. (1986). The rat brain in stereotaxic coordinates (2nd ed.). Orlando, FL: Academic Press.

Poremba, A.. \& Gabriel, M. (1999). Amygdala neurons mediate acquisition but not maintenance of instrumental avoidance behavior in rabbits. Journal of Neuroscience, 19, 9635-9641.

Russchen, F. T.. \& Price. J. L. (1984). Amygdalostriatal projections in the rat: Topographical organization and fiber morphology shown using the lectin PHA-L as an anterograde tracer. Neuroscience' Letters, 47, 15-22.

SCheChteR, M. D., \& CalCagnetTI, D. J. (1993). Trends in place preference conditioning with a cross-indexed bibliography; 1957-1991. Neuroscience \& Biohehavioral Reviews, 17, 21-41.

Tenovnik, E. J., \& Sommer, M. A. (1997). Effective spread and timecourse of neural inactivation caused by lidocaine injection in monkey cerebral cortex. Journal of Neuroscience Methods, 74, 17-26.

WHITE, N. M.. \& CARR, G. D. (1985). The conditioned place preference is affected by two independent reinforcement processes. Pharmacologv. Biochemistry \& Behavior, 23, 37-42.

(Manuscript received December 28, 1999; revision accepted for publication April 5, 2000.) 